\title{
What Supports Startups Need From Science and Technology Parks
}

\author{
Daniel C. Lee ${ }^{1}$, Xu Feng ${ }^{2} \&$ Yangmin Xiong ${ }^{2}$ \\ ${ }^{1}$ Department of Finance Law, and Real Estate, College of Business and Economics, California State University Los \\ Angeles, Los Angeles, USA \\ ${ }^{2}$ College of Business, Southwest Minzu University, Chengdu, Sichuan, China \\ Correspondence: Daniel C. Lee, Department of Finance, Law, and Real Estate, College of Business and Economics, \\ California State University Los Angeles, Los Angeles, USA. Tel: 323-343-2870. E-mail: dlee2@ calstatela.edu
}

Received: September 15, 2021

Accepted: October 7, 2021

Online Published: October 13, 2021

doi:10.5430/ijfr.v12n5p211

URL: https://doi.org/10.5430/ijfr.v12n5p211

\begin{abstract}
This study establishes strategies for the science and technology park (STP) operators to develop the support their hosted companies/startups (HCs) need to improve their performance at different stages of maturity. Unlike most of the research concentrated on the STP's viewpoints or used the after-the-fact results to create the policy guidelines for the operators, our paper uses the opposite approach by directly asking the HCs regarding what they need. From our survey results, we have identified two different strategies for improving HCs' performance. A comprehensive internal incubation network is necessary for any startup in a relatively mature development stage but with short settled years. On the other hand, a robust external incubation network is crucial for small-size startups in a low level of development stage but with long-settled years at STPs. We hope that the methodology underpinned in this study could open a new window for future research to better aid HCs in an STP.
\end{abstract}

Keywords: fuzzy-set qualitative comparative analysis (fsQCA), hosted companies/startups, incubation networks, science and technology parks

\section{Introduction}

Establishing and operating science and technology parks (hereafter STPs) are essential in the regional economic context. They are the policy tools for meeting a variety of financial and socioeconomic goals. Sometimes local governments will create designated technology corridors to attract high-tech companies to boost the local economy and employment growth. Typical STPs have large-scale campuses that house everything from corporate, government, or university labs to tiny startups. On the other hand, business incubators typically dedicate services only to startups. In this paper, we will treat incubators as parts of the STPs. Most of the real estate developers and campus designers of STPs know that firms engaged in high-tech activities often need to locate near one another or in STPs to enjoy the benefits of agglomerative effects (Koh et al., 2005). Close to a nearby university or research centers where technical expertise may be available is one of the essential criteria for site selection. However, to operate successful STPs, a more in-depth and in-detail assessment will be needed. Based on the assessment results, the park operators can design managerial policies and business operating models to help the new parks or those in their initial growth phase offer the business support functions and services needed by various hosted companies.

\section{Literature Review}

Guadix, Carrillo-Castrillo, Onieva, and Navascués (2016) reviewed a series of business models and operation strategies trying to identify the variables of parks that influence success. They used the information from ten parks with different characteristics and management strategies in Andalusia, Spain. They selected the important variables appearing in the literature concerning the advancement of STPs and the available data from the previous qualitative study and the Questionnaire that the parks filled. Using a qualitative viewpoint approach, they classified these ten parks into four groups according to their operating characteristics. Using the revenue as the proxy variable representing the success of the STPs and startups/hosted companies (hereafter HCs) in their study, the results yield a complex solution with three identifiable groups of parks, each constituting a different model. They also observed that the four un-identifiable parks shared similar characteristics, such as having a lower output than the average and suffering lower labor turnover and employment relative to other parks under study. Guadix et al. (2016) suggested three strategies resulting from the same research for the four un-identifiable parks' managers to implement to 
improve the park's performance. However, we believe their advice may not be appropriate since those parks are heterogeneous (Albahari et al., 2013).

The fsQCA method they used allows them to identify the variables that positively influence the STPs' performance and those of having no relevant importance in the study. However, the fsQCA method could not evaluate the variables not included in the model. It becomes clear that although their research added contributions to the existing literature but is still incomplete. The fourth group of the un-identifiable STPs and their equivalents require additional study. Guadix et al. (2016) observed that those STPs shared similar characteristics: short operation periods (i.e., young age), small sizes (defined by the number of employees and founders), lower labor turnover, and employment than the other parks. They also observed that the process from creating an STP until that STP reaches a critical number of HCs to gain financial independence is slow and complex. To overcome this situation, the managers need to implement strategies to foster the parks' development, which will be complicated. Moreover, the even more significant challenge faced by the managers is defining success in a manner that enables comparisons among STPs (Kharabsheh, 2012).

Some empirical studies concluded that locating within an STP is beneficial to the companies. For example, Albahari et al. (2013) listed several benefits that could positively affect the performance of the hosted companies, including creating external collaborations, improved research achievements, and support for applying for patents. They suggested that STPs can create a supportive space for new companies based on knowledge and technology, including facilitating technology transfer, attracting companies at the head of a technology sector, or promoting HCs' growth.

Guadix et al. (2016) observed that the studies aiming to determine the success or failure of STPs tend to focus on two areas: benefits that the park or the community obtains and benefits the hosted companies perceive. However, the lack of an established definition of success or a standard procedure to measure a company's performance makes it difficult to quantify an STP's effect on a hosted company.

Since people vote by their feet, if HCs were willing to move into an STP, they must believe that it would benefit them from residing there. In this paper, we will use the HCs' perceived benefits as the basis to find out what the HCs need from STPs to foster their firms' growth. This study will focus on the factors and outcomes such as performance evaluation, innovation orientation, and internal and external networks needed by HCs to prosper.

\section{Definition of the Input and Output Variables Used in This Study}

\subsection{Performance of Startups/Hosted Companies (HCs)}

Current research on the performance evaluation for HCs has taken two approaches: innovation versus entrepreneurial performance. The innovation performance focused on the importance of $R \& D$ benefits such as innovation results and efficiency. It reflected the connotations of value co-creation between various network subjects and HCs (Diao \& Su, 2008). Other studies also emphasized the critical role of innovation orientation (Y. Wang, Liu, \& Wang, 2019) and network structure (Ahuja, 2000) in innovation performance.

Entrepreneurial performance focused on economic benefits such as enterprise profitability and market share. It reflected the degree of satisfaction of HCs compared with the actual situation and expectation (Deshpandee, Grinstein, Kim, \& Ofek, 2013). Previous studies also explored the effects of innovation orientation (Z. M. Wang \& Liu, 2005) and network structure (B. Zhang, Sun, Pei, \& Qi, 2015) on entrepreneurial performance from different perspectives.

Discussing the innovation performance or entrepreneurial performance of HCs individually and independently cannot fully evaluate the contribution of STPs. As Li and Ren (2018) argued, STPs, as innovation incubators, should emphasize the combined results of innovation and entrepreneurship performance. As a result, we include both innovation and entrepreneurial performance (Xiong, Yang, \& Jia, 2019) as the evaluation variables in this study.

As used by Chen (2009) and Bell (2005), our paper uses the following three variables in the survey questions to measure the entrepreneurial performance: 1) the rate of return on investment, 2) the level of customer satisfaction, and 3) creating new products and getting new business, and the other six variables to measure the innovation performance: 4) improving existing products' quality, 5) satisfying market demand, 6) cost-cutting, 7) developing new products, 8) adopting new technologies, and 9) exploring new markets.

\subsection{Innovation Orientation Variables}

Startups usually create their culture spontaneously based on their interests. Having innovative ideas continuously and the desire to share them to turn their ideas into reality are the forces to form the startup culture (Y. M. Wang \& Ye, 2015). However, STPs' promotion of innovation is also indispensable (Li \& Ren, 2018). The emphasis on innovation 
at STPs is the primary motivation for the startups to move in and become participants in its ecosystem. It is now a common belief that STPs could cultivate the culture in HCs by enforcing innovation orientation within the campus.

Siguaw, Simpson, \& Enz (2006) integrated articles on innovation orientation from the literature on innovation, management, and marketing in the past 35 years and conceptually defined innovation orientation as a system concept based on knowledge-based theory and resource-based view. They first define innovation orientation as a knowledge structure consisting of learning philosophy, strategic direction, and trans-functional beliefs. A framework then was established to understand innovation orientation and its consequences in an organizational environment. They concluded that such emphasis on innovation should be regarded as a strategic orientation policy rather than specific innovation activity. Their works further support the observation provided by O'Reilly and Tushman (2013); in an environment of uncertainty, dynamics, ambiguity, and complexity, successful mature firms typically rely more on an overall innovation orientation policy that generates the innovation ability rather than on specific innovation projects. In the strategic aspect, innovation orientation emphasizing continuous innovation, learning, sharing, diversity, and cooperation is in tune with the HCs' culture. Their conclusions are consistent with the core spirit of HCs in STPs, as observed by Y. M. Wang and Ye (2015).

In recent years, the research on innovation orientation mainly regarded different types of firms as the research objects, explored the mechanism of knowledge exploration (Tian, 2011), manufacturing (J. Zhang \& Duan, 2010), and innovation orientated $(\mathrm{He}, \mathrm{He}, \& \mathrm{Hu}, 2014)$ firms, while ignoring the study on the impact of innovation orientation of STPs as a platform on HCs.

As used by Chun-yan (2009) and Xing and Wang (2015), our paper adopts the following five variables/questions in the Questionnaire to survey the innovation-related business practice: 1) emphasizing R\&D, technology-leading products/services, 2) encouraging HCs to innovate in product technology, marketing, and management, 3) supporting new products/services that are only having a small part of the improvement, 4) encouraging HCs to pay close attention to market trends and customer needs, and 5) encouraging HCs to introduce new products or ideas before their competitors do.

\subsection{Incubation Networks Variables}

Jia, Lei, \& Wang (2017) applied the concept of ecology to their studies and defined innovative products as the substance and knowledge and experience as the information in STPs' study. They argued that to help improve the performance of HCs, STPs need to build channels for the effective exchange of substance and information. As a result, STPs should create an incubation network structure to support various substance and information exchanges. Many studies have proven that startups can further overcome some typical disadvantages faced by most new entrants in the business world, such as liability of newness (Aldrich \& Auster, 1986) and smallness (Stinchcombe, 1965), by taking advantage of the incubation networks provided by STPs.

This paper argues that a complete network structure should consist of both the internal and external incubation networks to provide more abundant exchange channels. A well-established internal network indicates the existence of various channels closely connecting STPs and HCs. In contrast, a well-established external network requires STPs to closely connect with investment and financing institutions and other external objects (Hoang \& Antoncic, 2003). Moreover, Li and Ren (2018) emphasized that STPs need to act as platforms. They can help HCs establish contact with external stakeholders and provide potential resources such as investment, financing, sales, production, and creating economic and social profits through technological innovation.

As used by Lin, Wood, \& Lu (2012), our paper uses the following eight variables/questions in the Questionnaire to survey the usage of the internal incubation network for business practice: 1) communicating within STPs, and the following seven variables for the external incubation network: 2) connecting with government departments, 3) connecting with financial institutions, 4) connecting with intermediary services, 5) connecting with industry associations and chambers of commerce, 6 ) connecting with universities and research institutions.

\subsection{HCs' Development Stage, Size and Settled Years Variables}

HCs' development stage, size, and settled years are also considered in this study because these factors could influence the effectiveness of STPs' incubation. We also want to find out if HCs' essential needs might vary with the different development stages.

In the more mature stage, the HCs typically enjoy more sophisticated organizational architecture and work procedures. The startup's size is measured by the number of current employees and founders in the firm (Sigmund, Semrau, \& Wegner, 2015). Evidence has shown that the numbers of workers are paramount for startups in terms of survival (Brüderl, Preisendörfer, \& Ziegler, 1992) and developing opportunities (Baker \& Nelson, 2005; Sun \& 
Wang, 2014). And the settled years show the length of time that a startup has stayed in the park. We use these three variables to differentiate $\mathrm{HCs}$ in our study. In addition, we also classify all $\mathrm{HCs}$ according to the types of industries to reflect the coverage of various industrial sectors in this study.

\section{Research Design}

\subsection{Research Method Selection and Logical Framework}

We choose the fuzzy-set qualitative comparative analysis (fsQCA) as the research method for two reasons.

1) As demonstrated by Y. L. Zhang and Bai (2017), STPs have the characteristics of self-organization, non-linearity, multi-subject collaborative Governance, and multi-sharing, which is consistent with complexity science (Brian Arthur, 1999). Hou, Jin, and Wu (2016) further characterized this kind of ecosystem as a complex adaptive system, which is unsuitable for using the traditional linear hypothesis research (Douglas, Shepherd, \& Prentice, 2020). As a result, we decided to use a qualitative and quantitative mixed-method like the fsQCA to study the ecosystem of STPs with the complexity characteristics as Roundy, Bradshaw, \& Brockman (2018) suggested.

2) From the perspective of analyzing variables, the traditional linear hypothesis method cannot verify whether or not the high performance of HCs was due to the combined or synergistic effect of energy (i.e., innovation orientation), substance, and information. On the other hand, fsQCA can identify the potential interdependence between antecedent variables and reveal multiple equally compelling paths to the same result (Douglas et al., 2020). This very nature of the fsQCA method makes it a perfect tool to explore the configuration effect in this paper.

This research tool is available by using the fsQCA software or R language. The fsQCA method has been used more and more in management and entrepreneurial literature (e.g., Douglas et al., 2020; Fiss, 2011; Greckhamer, 2016). In this paper, we use the fsQCA 3.0 version of the software for the research.

\subsection{Questionnaire Format and Samples Collection Procedures}

Our Questionnaire used a Likert five scale, divided into five grades from "completely disagree" to "completely agree." We have selected the managers or core technicians who knew the development trends of the HCs for the survey. The respondents promised to fill out the form truthfully and anonymously according to the actual situation. Appendix A shows the summary of the questions used in the Questionnaire.

Only the HCs that are officially established and continue to honor the incubation agreement during the survey period were selected to ensure data quality. We used the dataset of the HCs inside the STPs located in Chengdu, Beijing, and Shenzhen, China. A total of 210 valid samples were finally obtained, with various sample characteristics. After the test of common method bias and analysis of variable reliability and validity, we classify the dataset into different categories based on calibration and boolean analysis (Douglas et al., 2020; Ragin \& Fiss, 2008). The details are shown in Table 1 below.

Table 1. Sample characteristics $(\mathrm{N}=210)$.

\begin{tabular}{lcclcc}
\hline \multicolumn{1}{c}{ Industry } & Number & Percentage (\%) & \multicolumn{1}{c}{ Size(people) } & Number & Percentage (\%) \\
\hline Electronic Information & 43 & 20.5 & Less than5 & 34 & 16.2 \\
Biological Medicine & 15 & 7.1 & $5-10$ & 63 & 30.0 \\
$\begin{array}{l}\text { Modern Service Industry (e.g., } \\
\text { financial, logistics, educational }\end{array}$ & 38 & 18.1 & $10-20$ & 56 & 26.7 \\
and catering service, etc.) & & & & & \\
Agriculture & 17 & 8.1 & $20-50$ & 21 & 10.0 \\
Petroleum Chemical Industry & 2 & 1.0 & More than 50 & 36 & 17.1 \\
The New Material & 2 & 1.0 & Settled Years & Number & Percentage (\%) \\
New Energy & 6 & 2.9 & Within half a year & 49 & 23.3 \\
Financial & 13 & 6.2 & Six months - 1 year & 52 & 24.8 \\
IT & 41 & 19.5 & 1 year - 2 years & 44 & 21.0 \\
Other & 33 & 15.7 & 2 years - 3 years & 35 & 16.7
\end{tabular}




\section{Development Stage}

Research\& Development Period

Initial Trial Period

Pilot Period

Marketing Period

$\begin{array}{cclcc}\text { Number } & \text { Percentage (\%) } & \text { 3years }- \text { 4years } & 12 & 5.7 \\ 47 & 22.4 & \text { More than 4 years } & 18 & 8.6 \\ 61 & 29.0 & & & \\ 46 & 21.9 & & & \\ 55 & 26.2 & & \end{array}$

\section{Method}

\subsection{Fuzzy-Set Qualitative Comparative Analysis Results}

In a nutshell, we classify the dataset into different categories by transforming variables' raw scores into fuzzy-set membership scores that range from 0 to 1 using three anchors and based on log-odds of full membership (Douglas et al., 2020; Fiss, 2011). The higher the variable value is, the closer its fuzzy-set membership score is to 1 (Douglas et al., 2020; Fiss, 2011). We also conducted boolean analysis combined with some constraints to simplify the configuration in the truth table.

We chose the performance and negation set of performance as outcome variables. We converted the fuzzy-set membership score into a Truth Table in which variables score only includes 0 and 1 representing either absence or presence of related variable respectively (Ragin \& Fiss, 2008). We coded high performance if the performance value is one and related configuration meets the constraints. On the other hand, we coded low performance if the negation of performance value is one and related configuration meets the constraints (Douglas et al., 2020).

Table 2 below presents the truth table, which details the calibrated scores for the relevant cases on the outcome and causal conditions. Truth Table construction aims to identify explicit connections between combinations of causal conditions and results (Ragin \& Fiss, 2008). There are 15 rows in the Truth Table representing the number of logically possible combinations of causal conditions. The row includes both the reminders and observed cases. The column with the heading "Number" shows the number of related cases belonging to it. The constraints we set for RAW, PRI, and frequency thresholds are $0.8,0.65$, and 2 , respectively.

Table 2. Truth table

\begin{tabular}{ccccccccccc}
\hline DS. & SZ & SY & IO & IIN & IEN & Number & Performance & Raw consist & PRI consist & SYM consist \\
\hline 0 & 0 & 1 & 1 & 1 & 1 & 3 & 1 & 0.966541 & 0.917334 & 0.917333 \\
1 & 0 & 1 & 1 & 1 & 1 & 1 & 1 & 0.928111 & 0.801191 & 0.801191 \\
1 & 1 & 0 & 1 & 1 & 1 & 5 & 1 & 0.923447 & 0.809239 & 0.819758 \\
1 & 1 & 1 & 1 & 1 & 1 & 1 & 1 & 0.921451 & 0.725905 & 0.731411 \\
0 & 0 & 0 & 1 & 1 & 1 & 1 & 1 & 0.894938 & 0.755077 & 0.755076 \\
1 & 0 & 0 & 1 & 1 & 1 & 2 & 1 & 0.885288 & 0.749603 & 0.750797 \\
1 & 1 & 0 & 0 & 1 & 1 & 1 & 0 & 0.919739 & 0.545455 & 0.545455 \\
1 & 1 & 1 & 0 & 1 & 1 & 1 & 0 & 0.905237 & 0.309092 & 0.309091 \\
0 & 0 & 0 & 1 & 0 & 1 & 1 & 0 & 0.879541 & 0.640000 & 0.640000 \\
1 & 0 & 1 & 0 & 1 & 0 & 1 & 0 & 0.815417 & 0.365767 & 0.365766 \\
0 & 1 & 0 & 1 & 0 & 0 & 2 & 0 & 0.810640 & 0.192308 & 0.196850 \\
1 & 1 & 0 & 1 & 0 & 0 & 1 & 0 & 0.798500 & 0.221533 & 0.221532 \\
0 & 0 & 1 & 0 & 0 & 0 & 1 & 0 & 0.765840 & 0.285714 & 0.285714 \\
1 & 0 & 1 & 0 & 0 & 0 & 6 & 0 & 0.680660 & 0.236052 & 0.245317 \\
0 & 1 & 0 & 0 & 0 & 0 & 2 & 0 & 0.660148 & 0.075229 & 0.075229
\end{tabular}

Note: DS: development stage; SZ: size; SY: settled years; IO: innovation orientation; IIN: incubated internal network; IEN: incubated external network. 


\subsection{Common Method Bias Test and Variable Reliability and Validity Analysis}

The results of AMOS for the single-factor CFA test showed that there was no significant common method bias (Podsakoff, MacKenzie, Lee, \& Podsakoff, 2003), while the single-factor EFA test showed that there was no significant common method deviation in this study (Podsakoff and Organ, 1986).

The principal component analysis also indicated that our data is suitable for factor analysis (Hao, Zhang, Liu, \& Yang, 2018). Exploratory factor analysis further confirmed good reliability coefficients and no cross-factor problem for each item. Confirmatory factor analysis conducted by AMOS finally endorsed good construct validity for the scale used and good structural validity.

\subsection{Calibration}

The purpose of calibration is to make the variables measurement explicable and meaningful, and its specific logic is to consider both kind-difference and degree-difference between cases (Greckhamer, Furnari, Fiss, \& Aguilera, 2018). As Du, Pan, Zhou, and Ouyang (2018) suggested, in our fsQCA study we classified HCs based on theoretical and situational knowledge. For example, if they are highly mature and profitable IT firms, they should belong to a low-performance group. Otherwise, if they are young startups, they belong to a high-performance group.

As Ragin and Fiss (2008) suggested, researchers can calibrate fuzzy sets according to the degree of membership corresponding to theoretical constructs. In the decision process, we set three anchor points: full-membership, non-membership, and crossover point. Between the full-membership and the non-membership, the crossover point is the maximum ambiguity point in assessing whether a case is within or outside of a set. When the variable value of cases exceeds the value of the full-membership point, its fuzzy-set membership score is 1; when the variable value of the cases is lower than the value of the non-membership point, its fuzzy-set membership score is 0 .

We follow Douglas et al. (2020) to calibrate the survey results by using the median value as the crossover point, then adding or subtracting one standard deviation from the median value for the full-membership and non-membership anchor points. Then we use fullyin, max'mambig, and fullyout to represent the full-membership, crossover point, and non-membership, respectively (Douglas et al., 2020). Table 3 presents the results.

Table 3. Sample statistics and calibration parameters for fsQCA

\begin{tabular}{lcccccccc}
\hline \multicolumn{1}{c}{ Variable } & Mean & Std dev & Min & Max & Median & Fullyin & Max'mambig & Fullyout \\
\hline Development stage & 2.533 & 1.120 & 1.000 & 5.000 & 2.000 & 3.118 & 2.000 & 0.882 \\
Size & 2.819 & 1.307 & 1.000 & 5.000 & 3.000 & 4.304 & 3.000 & 1.696 \\
Settled years & 2.824 & 1.526 & 1.000 & 6.000 & 3.000 & 4.522 & 3.000 & 1.478 \\
Innovation orientation & 3.748 & 0.825 & 1.000 & 5.000 & 3.800 & 4.623 & 3.800 & 2.977 \\
Incubation internal network & 3.762 & 1.031 & 1.000 & 5.000 & 4.000 & 5.028 & 4.000 & 2.972 \\
Incubation external network & 3.688 & 0.760 & 1.000 & 5.000 & 3.710 & 4.468 & 3.710 & 2.952 \\
Performance & 3.830 & 0.650 & 1.700 & 4.830 & 3.970 & 4.619 & 3.970 & 3.321 \\
\hline
\end{tabular}

\section{Discussion}

\subsection{Necessity Analysis}

The assessments of set relations are essential in analyzing explicit connections, similar to the assessments of significance and strength in the study of the correlational relationships. The value of consistency is used to evaluate the necessity of a single condition. It is pointless to consider the value of coverage that would turn out to be some common-sense conclusions (Ragin \& Fiss, 2008).

Consistency represents the proportion of the total cases consistent with the outcome variable in the same configuration, like significance, which indicates to what extent the cases of the specific configuration are subsets for the outcome variable (Ragin \& Fiss, 2008). Coverage represents the proportion of the total cases of the outcome can be explained by the cases of specific configuration, like strength, which indicates the empirical relevance or importance of a set-theoretic connection. In this paper, the consistency score of 0.9 was selected as the threshold value (M. R. Schneider, Schulze-Bentrop \& Paunescu, 2010) to determine the existence of a necessary condition. As shown in Table 4, the consistency score of no-condition exceeds 0.9 . Therefore, no necessary condition exists. 
Table 4. Necessity analysis

\begin{tabular}{lcccc}
\hline \multirow{2}{*}{\multicolumn{1}{c}{ Condition variables }} & \multicolumn{4}{c}{ Outcome variables } \\
\cline { 2 - 5 } & \multicolumn{2}{c}{ High performance } & \multicolumn{2}{c}{ Low performance } \\
\cline { 2 - 5 } & Consistency & Coverage & Consistency & Coverage \\
\hline Development stage & 0.716276 & 0.531533 & 0.713428 & 0.600785 \\
$\sim$ Development stage & 0.462031 & 0.586906 & 0.443698 & 0.639592 \\
Size & 0.540409 & 0.598919 & 0.500313 & 0.629225 \\
$\sim$ Size & 0.665447 & 0.539920 & 0.681089 & 0.627103 \\
Settled years & 0.551083 & 0.603809 & 0.497357 & 0.618401 \\
$\sim$ Settled years & 0.651723 & 0.533272 & 0.681358 & 0.632673 \\
Innovation orientation & 0.813561 & 0.746827 & 0.509540 & 0.530795 \\
$\sim$ Innovation orientation & 0.488869 & 0.467620 & 0.756965 & 0.821665 \\
Incubation internal network & 0.757549 & 0.765092 & 0.494491 & 0.566735 \\
$\sim$ Incubation internal network & 0.571008 & 0.498846 & 0.795037 & 0.788189 \\
Incubation external network & 0.830944 & 0.774566 & 0.465377 & 0.492277 \\
$\sim$ Incubation external network & 0.455322 & 0.428736 & 0.786885 & 0.840816 \\
\hline
\end{tabular}

Note: symbol " " representing "Negation" or the variable that is without existence.

\subsection{Sufficient Analysis}

We make some constraints for identifying high performance. We set the consistency threshold at 0.80; PRI consistency cut-off value at 0.65; frequency threshold at 2 (Douglas et al., 2020; C. Q. Schneider \& Wagemann, 2012). The sufficient analysis by fsQCA software transformed the information, including all logical remainders, and converted the outcome to establish Table 5 with two configurations, namely 1 and 2 . The result consists of different categories of consistency and coverage. The consistency for configurations 1 and 2 are 0.900 and 0.967 , respectively, indicating that the specific configuration is a subset solution, of the degree higher than the consistency standard of 0.8 ; and the solution consistency and coverage are 0.917 and 0.486 . Finally, we can conclude that the solution can explain the results reasonably (Ragin \& Fiss, 2008; M. R. Schneider et al., 2010).

Table 5. Sufficient analysis of high performance

\begin{tabular}{|c|c|c|}
\hline Conditions for configuration & 1 & 2 \\
\hline Development stage & $\bullet$ & $\otimes$ \\
\hline Size & & $\otimes$ \\
\hline Settled years & $\otimes$ & - \\
\hline Innovation orientation & $\bullet$ & $\bullet$ \\
\hline Incubation internal network & 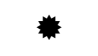 & $\bullet$ \\
\hline Incubation external network & $\bullet$ & $*$ \\
\hline Consistency & 0.900 & 0.967 \\
\hline Raw coverage & 0.391 & 0.182 \\
\hline Unique coverage & 0.303 & 0.095 \\
\hline Solution consistency & & \\
\hline Solution coverage & & \\
\hline
\end{tabular}

Note: indicates that the core condition exists, $\bigcirc$ indicates that the core condition is absent, $\bullet$ indicates that the peripheral condition exists, $\otimes$ indicates that the peripheral condition is absent, blank spaces indicate "do not care," the same below. 


\subsection{Robustness Test}

We conducted different robustness tests. First, we reprocessed the data by modifying the calibration anchors, including 20th, 50th, and 80th, and re-ran the pooled analysis for the calibrated data. The configurations generated were identical to our original findings. Second, we altered the PRI thresholds from 0.65 to 0.70 , which didn't change the result. Third, we changed the consistency threshold from 0.80 to up (+0.50) and down ( -0.50$)$. These results are still consistent with our original analysis. Therefore, the outcomes of different robustness tests were similar to those tables presented in this study.

\section{Conclusions}

The debate on the effectiveness of STPs as tools for improving the performance of hosted companies remains open. One school of authors (Colombo \& Delmastro, 2002; Macdonald, 1987; Massey, Quintas, \& Wield, 1992; M. Zhang, Lan, Chen, \& Zeng, 2020) argue that STPs do not have any relevant effect on the outcomes of hosted companies. On the other hand, another school of authors (e.g., Albahari et al., 2013) argue that STPs can create a supportive space for new companies based on knowledge, technology, facilitating technology transfer, promoting companies' growth, and attracting companies at the head of a technology sector. Hence, it is beneficial for companies to dwell in a park.

It is now common for HCs to receive services from the parks such as broadband connection, video conferencing, meeting rooms, events management, administrative support, etc. Some professional services either directly from the parks or indirectly from other companies (following the park's indications) are also available, such as accounting, tutoring, assessment of funding risk, marketing, development of advertising campaigns, seeking funding for capital and operating purposes, presenting investment projects to the possible financiers, improving research performance, applying for patents, creating external collaborations, and facilitating cooperation with other institutions, such as research centers and regional agencies, etc. However, the parks the HCs resided in are heterogeneous. Albahari et al. (2013) assessed the effect of the heterogeneity of the parks on the innovation performance of the HCs. They concluded that some parks work properly and generate values for HCs, whereas others are unsuccessful.

Guadix et al. (2016) used the identified variables that influence the success of the parks to develop three strategies. They recommended the four parks that failed to be included in the three identifiable groups to implement for improving the HCs' and park's performance. We believe the advice may be ineffective because variables that are effective to mature and large HCs may not be relevant to young and small startups since different HCs have different needs.

In this paper, we took a direct approach to study what HCs need from STPs. Using the fuzzy-set qualitative comparative analysis (fsQCA) method to study the survey results, we have identified two packages of supports required by two different types of HCs respectively for improving performance:

1) For startups of any size in a relatively mature development stage but with short settled years, creating a robust internal incubation network by STPs is essential in improving HCs' performance. Emphasizing and fostering the culture of innovation orientation and creating external incubation networks played only peripheral roles. Such startups with short settled years may not yet familiarize themselves with the STPs' internal incubation network. The STPs need to provide and promote the essential internal supports in improving policies and regulations, determining development directions, expanding recruitment, and enhancing legitimacy.

2) For startups of small size in a relatively low level of development stage but with long-settled years, creating a robust external incubation network by STPs played a core role in improving HCs' performance. Emphasizing and fostering the culture of innovation orientation and creating internal incubation networks played only peripheral roles. Since such startups have settled in the STPs for a long time, they should have maximized the usages of the STPs' internal supports. However, now such startups mainly face the problems of having unmet demands for heterogeneous external resources. To achieve their goals for maintaining continuing growth or even survival in this stage is to connect them with abundant external heterogeneous resources. The social capital theory echoes our conclusion: the ability of enterprises to mobilize external resources, attract customers and discover entrepreneurial opportunities depends on the establishment of external networks, and the development of startups depends on high-value networks (Pennings et al., 1998).

\subsection{Limitations and Avenues for Future Research}

Firstly, although the fsQCA method can identify the configuration effect, the operation mechanism of HCs and the evolution of incubation networks in the STPs had dynamic characteristics. The questionnaire survey and data processing adopted in this study had time-lag problems. In the future, researchers may want to use timing QCA for dynamic tracking in a project that can generate time-series data. 
Secondly, this paper analyzes the data collected from different cities without making district difference adjustments. Each industrial district has its value pattern that reflects the market's reaction to its location and the characteristics of its infrastructure, including regulations and governmental policies. Some STPs may have unique features, and incubation modes are not included in the survey questionnaire but are typical or important in local areas. Future research may need to conduct comparative analysis among STPs located in different districts for in-depth discussion.

\section{References}

Ahuja, G. (2000). Collaboration networks, structural holes, and innovation: A longitudinal study. Administrative Science Quarterly, 45(3), 425-455. https://doi.org/10.2307/2667105

Albahari, A., Catalano, G., \& Landoni, P. (2013). Evaluation of national science park systems: A theoretical framework and its application to the Italian and Spanish systems. Technology Analysis \& Strategic Management, 25(5), 599-614. https://doi.org/10.1080/09537325.2013.785508

Aldrich, H., \& Auster, E. R. (1986). Even dwarfs started small: Liabilities of age and size and their strategic implications. Research in Organizational Behavior, 8, 165-186.

Baker, T., \& Nelson, R. E. (2005). Creating something from nothing: Resource construction through entrepreneurial bricolage. Administrative Science Quarterly, 50(3), 329-366. https://doi.org/10.2189/asqu.2005.50.3.329

Bell, G. G. (2005). Clusters, networks, and firm innovativeness. Strategic Management Journal, 26(3), 287-295. https://doi.org/10.1002/smj.448

Brian Arthur, W. (1999). Complexity and the economy. Science, 284(5411), 107-109. https://doi.org/10.1126/science.284.5411.107

Brüderl, J., Preisendörfer, P., \& Ziegler, R. (1992). Survival chances of newly founded business organizations. American Sociological Review, 57(2), 227-242. https://doi.org/10.2307/2096207

Chen, C.-J. (2009). Technology commercialization, incubator and venture capital, and new venture performance. Journal of Business Research, 62(1), 93-103. https://doi.org/10.1016/j.jbusres.2008.01.003

Chun-yan, X. (2009). The effects of strategic orientation on business performance: Innovation as mediator an empirical examination in the firms from Hunan province high-tech industrial development zone. Science of Science and Management of S. \&. T., 30, 156-163.

Colombo, M. G., \& Delmastro, M. (2002). How effective are technology incubators?: Evidence from Italy. Research Policy, 31(7), 1103-1122. https://doi.org/10.1016/S0048-7333(01)00178-0

Deshpandeé, R., Grinstein, A., Kim, S.-H., \& Ofek, E. (2013). Achievement motivation, strategic orientations and business performance in entrepreneurial firms: How different are Japanese and American founders?. International Marketing Review, 30(3), 231-252. https://doi.org/10.1108/02651331311321981

Diao, X. C., \& Su, J. Q. (2008). Measuring the performance of the eco-industrial networks in an industrial zone. Science Research Management, 20, 152-158. https://doi.org/10.19571/j.cnki.1000-2995.2008.03.019

Douglas, E. J., Shepherd, D. A., \& Prentice, C. (2020). Using fuzzy-set qualitative comparative analysis for a finer-grained understanding of entrepreneurship. Journal of Business Venturing, 35(1), Article 105970. https://doi.org/10.1016/j.jbusvent.2019.105970

Du, W., Pan, S. L., Zhou, N., \& Ouyang, T. (2018). From a marketplace of electronics to a digital entrepreneurial ecosystem (DEE): The emergence of a meta-organization in Zhongguancun, China. Information Systems Journal, 28(6), 1158-1175. https://doi.org/10.1111/isj.12176

Fiss, P. C. (2011). Building better causal theories: A fuzzy set approach to typologies in organization research. Academy of Management Journal, 54(2), 393-420. https://doi.org/10.5465/AMJ.2011.60263120

Greckhamer, T. (2016). CEO compensation in relation to worker compensation across countries: The configurational impact of country-level institutions. Strategic Management Journal, 37(4), 793-815. https://doi.org/10.1002/smj.2370

Greckhamer, T., Furnari, S., Fiss, P. C., \& Aguilera, R. V. (2018). Studying configurations with qualitative comparative analysis: Best practices in strategy and organization research. Strategic Organization, 16(4), 482-495. https://doi.org/10.1177/1476127018786487

Guadix, J., Carrillo-Castrillo, J., Onieva, L., \& Navascués, J. (2016). Success variables in science and technology parks. Journal of Business Research, 69(11), 4870-4875. https://doi.org/10.1016/j.jbusres.2016.04.045 
Hao, X. L., Zhang, Y. L., Liu, Y. R., \& Yang, J. (2018). Mercy or regret: A study of counterfactual thinking and entrepreneurial learning in entrepreneurial fail. Nankai Business Review, 21, 75-87.

He, J. H., He, C. Z., \& Hu, D. Y. (2014). Technological capability endowment, strategic innovation-oriented and the formation of innovative enterprises. Science \& Technology Progress and Policy, 31(22), 57-62. http://doi.org/10.6049/kjjbydc.2014070130

Hoang, H., \& Antoncic, B. (2003). Network-based research in entrepreneurship-A critical review. Journal of Business Venturing, 18(2), 165-187. https://doi.org/10.1016/S0883-9026(02)00081-2

Hou, X., Jin, X., \& Wu, J. (2016). On the characteristics and operation mechanism of the crowd innovation space from CAS perspective. Journal of Intelligence, 35(10), 195-200, 119. https://doi.org/10.3969/j.issn.1002-1965.2016.10.034

Jia, T., Lei, L., \& Wang, M. (2017). Maker-space ecosystem: Content, characteristic, construction and operation mechanism. Science and Technology Management Research, 37(11), 8-14. https://doi.org/10.3969/j.issn.1000-7695.2017.11.002

Kharabsheh, R. (2012). Critical success factors of technology parks in Australia. International Journal of Economics and Finance, 4(7), 57-66. https://doi.org/10.5539/ijef.v4n7p57

Koh, F. C. C., Koh, W. T. H., \& Tschang, F. T. (2005). An analytical framework for science parks and technology districts with an application to Singapore. Journal of Business Venturing, 20(2), 217-239. https://doi.org/10.1016/j.jbusvent.2003.12.002

Li, Z. H., \& Ren, Y. Y. (2018). The formation and influential mechanism of social capital of makerspace in the context of mass entrepreneurship and innovation. Studies in Science of Science, 36(8), 1487-1494, 1515. https://doi.org/10.3969/j.issn.1003-2053.2018.08.016

Lin, D., Wood, L. C., \& Lu, Q. (2012). Improving business incubator service performance in China: The role of networking resources and capabilities. The Service Industries Journal, 32(13), 2091-2114. https://doi.org/10.1080/02642069.2011.582498

Macdonald, S. (1987). British science parks: Reflections on the politics of high technology. R\&D Management, 17(1), 25-37. https://doi.org/10.1111/j.1467-9310.1987.tb00045.x

Massey, D., Quintas, P., \& Wield, D. (1992). High tech fantasies: Science parks in society, science and space. London: Routledge. https://doi.org/10.4324/9780203169360

O'Reilly, C. A., \& Tushman, M. L. (2013). Organizational ambidexterity: Past, present, and future. Academy of Management Perspectives, 27(4), 324-338. https://doi.org/10.5465/amp.2013.0025

Pennings, J. M., Lee, K., \& Witteloostuijn, A. V. (1998). Human capital, social capital, and firm dissolution. Academy of Management Journal, 41(4), 425-440. https://doi.org/10.5465/257082

Podsakoff, P. M., \& Organ, D. W. (1986). Self-reports in organizational research: Problems and prospects. Journal of Management, 12(4), 531-544. https://doi.org/10.1177/014920638601200408

Podsakoff, P. M., MacKenzie, S. B., Lee, J.-Y., \& Podsakoff, N. P. (2003). Common method biases in behavioral research: A critical review of the literature and recommended remedies. Journal of Applied Psychology, 88(5), 879-903. https://doi.org/10.1037/0021-9010.88.5.879

Ragin, C. C., \& Fiss, P. C. (2008). Net effects versus configurations: An empirical demonstration. In Redesigning social inquiry: Fuzzy sets and beyond (pp. 190-213). Chicago: University of Chicago Press.

Roundy, P. T., Bradshaw, M., \& Brockman, B. K. (2018). The emergence of entrepreneurial ecosystems: A complex adaptive systems approach. Journal of Business Research, 86, 1-10. https://doi.org/10.1016/j.jbusres.2018.01.032

Schneider, C. Q., \& Wagemann, C. (2012). Set-theoretic methods for the social sciences: A guide to qualitative comparative analysis. Cambridge University Press. https://doi.org/10.1017/CBO9781139004244

Schneider, M. R., Schulze-Bentrop, C., \& Paunescu, M. (2010). Mapping the institutional capital of high-tech firms: A fuzzy-set analysis of capitalist variety and export performance. Journal of International Business Studies, 4l(2), 246-266. https://doi.org/10.1057/jibs.2009.36

Sigmund, S., Semrau, T., \& Wegner, D. (2015). Networking ability and the financial performance of new ventures: Moderating effects of venture size, institutional environment, and their interaction. Journal of Small Business 
Management, 53(1), 266-283. https://doi.org/10.1111/jsbm.12009

Siguaw, J. A., Simpson, P. M., \& Enz, C. A. (2006). Conceptualizing innovation orientation: A framework for study and integration of innovation research. Journal of Product Innovation Management, 23, 556-574. https://doi.org/10.1111/j.1540-5885.2006.00224.x

Stinchcombe, A. L. (1965). Social structure and organizations. In J. G. March (Ed.), Handbook of organizations (pp. 142-193). Chicago: Rand McNally.

Sun, X. H., \& Wang, Y. (2014). The influence of firm size on productivity and its difference-Based on the empirical test of industrial firms in China. China Industrial Economics, 28, 57-69. https://doi.org/10.19581/j.cnki.ciejournal.2014.05.005

Tian, M. (2011). Study on relationship between innovation orientation and firm performance in knowledge intensive firms. Science and Technology Management Research, 31(24), 5-8. https://doi.org/10.3969/j.issn.1000-7695.2011.24.002

Wang, Y. M., \& Ye, A. M. (2015). From traditional maker space to new maker space: Functional model and service path based on innovation 2.0. E-Education Research, 35, 5-12. https://doi.org/10.13811/j.cnki.eer.2015.11.001

Wang, Y., Liu, M., \& Wang, S. (2019). Impact of organizational innovation orientation on innovation performance of R\&D personnel: Roles of creativity and error management atmosphere. Technology Economics, 38(1), 9-18. https://doi.org/10.3969/j.issn.1002-980X.2019.01.002

Wang, Z. M., \& Liu, B. C. (2005). Technological capability and entrepreneurial performance: A strategic orientation perspective. Studies in Science of Science, 23(6), 765-771. https://doi.org/10.3969/j.issn.1003-2053.2005.06.009

Xing, R., \& Wang, G. H. (2015). Entrepreneurial orientation, innovation intention and startups' innovation performance-The moderating role of incubation environment. R\&D Management, $27,100-112$. https://doi.org/10.13581/j.cnki.rdm.2015.01.014

Xiong, L., Yang, Y., \& Jia, J. F. (2019). "Can do" and "want to do": The impact of dual entrepreneurial improvisation on entrepreneurial performance-based on drive. Management World, 35, 137-151. https://doi.org/10.19744/j.cnki.11-1235/f.2019.0168

Zhang, B., Sun, G., Pei, M., \& Qi, P. (2015). Network competence, network structure and entrepreneurial performance: Study based on empirical analysis of China incubation industry. Nankai Business Review, 18(2), 39-50. https://doi.org/10.3969/j.issn.1008-3448.2015.02.005

Zhang, J., \& Duan, Y. L. (2010). The role of market orientation and innovation orientation in new product performance: An empirical evidence from Chinese manufacturers. Nankai Business Review, 13(1), 81-89. https://doi.org/10.3969/j.issn.1008-3448.2010.01.010

Zhang, M., Lan, H. L., Chen, W. H., \& Zeng, P. (2020). Research on the antecedent configuration and performance of strategic change. Manag World, 36, 168-185. https://doi.org/10.19744/j.cnki.11-1235/f.2020.0145

Zhang, Y. L., \& Bai, F. (2017). Research on entrepreneurship ecosystem evolution and optimization based on dissipative theory. Science of Science and Management of S. \&. T., 38, 22-29.

\section{Appendix}

\section{Questions Used in the Questionnaire}

\section{Part I: The basic information of the startups}

1. Size of startups:

(1) Less than 5 people (2) 5-10 people (3) 10-20 people (4) 20-50 people (5) More than 50 people

2. The number of years your company has entered:

(1) less than half year (2) half a year - within a year (3) 1-2 years (4) 2-3 years (5) 3-4 years (6) more than 4 years

3. Industry of your company:

A. Electronic information 

B. Biological medicine
C. Modern service industry
D. Agricultural
E. Petrochemicals
F. New materials
G. New energy
H. Finance
I. IT

J. Others (please specify):

4. The current development stage of your company:

(1) Research and development period (2) Initial trial period (3) Pilot period (4) Marketing period

\section{Part II : Construct Scale}

1. Innovation Orientation:

(1) Incubators tend to emphasize $\mathrm{R} \& \mathrm{D}$, technology-leading products/services

(2) Incubators always encourage companies to innovate in product technology, marketing, and management

(3) Incubators support new products/services that are only having a small part of the improvement

(4) Incubators encourage companies to pay close attention to market trends and customer needs

(5) Incubators encourage companies to introduce new products or ideas before their competitors

2. Network Structure:

(1) High frequency of communication with incubators

(2) Incubators help companies connect with government departments

(3) Incubators help businesses connect with financial institutions

(4) Incubators help businesses connect with intermediary services

(5) Incubators help companies connect with industry associations and chambers of commerce

(6) Incubators help companies connect with universities and research institutions

3. Innovation Performance:

(1) The quality of existing products has been improved

(2) The existing market demand has been basically satisfied

(3) Production/service costs are reduced

(4) Firms are constantly developing new products/services

(5) Startups are constantly introducing new processes or technologies

(6) The firms are actively exploring new markets

4. Entrepreneurial Performance:

(1) Compared with my peers, I can earn an extremely high rate of return on investment

(2) Compared with my peers, I can achieve extremely high customer satisfaction

(3) Compared with my peers, I get more new products and new business

\section{Copyrights}

Copyright for this article is retained by the author(s), with first publication rights granted to the journal.

This is an open-access article distributed under the terms and conditions of the Creative Commons Attribution license (http://creativecommons.org/licenses/by/4.0/). 